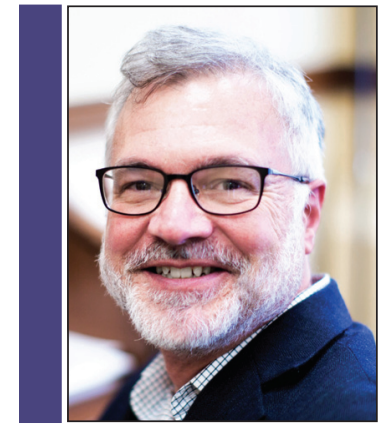

Cahill to receive MRS Innovation in Materials Characterization Award

$\mathrm{D}$ avid Cahill, Willett Professor and Head of the Department of Materials Science and Engineering at the University of Illinois at Urbana-Champaign (UIUC), is being honored with the Materials Research Society (MRS) Innovation in Materials Characterization Award "for developing transformative methods for characterizing the thermal transport properties of materials and their interfaces using time-domain thermoreflectance and related approaches." He will receive the award at the 2018 MRS Spring Meeting in Phoenix, Ariz. The award is endowed by Gwo-Ching Wang and Toh-Ming Lu.

Time-domain thermoreflectance (TDTR), as implemented and refined by Cahill over the past decade, has become a standard method for accurate quantification of the thermal conductivity of thin films/layers and small samples of materials, and thus has been a critical aspect of the growing discipline of nanoscale thermal transport. TDTR is used in dozens of laboratories around the world and is having a critical impact on industry, particularly within magnetic recording.

Cahill's group studies the basic science of thermal transport in materials, with a particular emphasis on the exchange of thermal energy at solid-solid and solidliquid interfaces. They recently developed powerful methods of characterizing nanoscale thermal transport using the ultrafast laser metrology of precisely controlled thin-film multilayers and suspensions of metallic nanoparticles. His current research focuses on developing an understanding of thermal transport at the nanoscale; the development of new methods of materials processing and analysis using ultrafast optical techniques; and advancing a fundamental understanding of interfaces between materials and water.

Cahill received his BS degree in engineering physics from The Ohio State University and his $\mathrm{PhD}$ degree in physics from Cornell University in 1989. His doctoral work concerned lattice vibrations of disordered solids. Before joining the faculty at UIUC, he worked at IBM Watson Research Center, where he conducted research on metal-semiconductor interfaces. Cahill received the Yeram S. Touloukian Award from the American Society of Mechanical Engineers in 2015, was named a University Scholar by the University of Illinois in 2001, and a Willett Professor of Engineering by the College of Engineering in 2005 . He is a Fellow of the American Vacuum Society, the American Physical Society, and the Materials Research Society. He has published approximately 300 articles and is on the editorial boards of Applied Physics Letters and the Journal of Applied Physics.

Cahill will be recognized at the Awards Ceremony and will present his talk on Wednesday, April 4 at the Phoenix Convention Center (PCC).

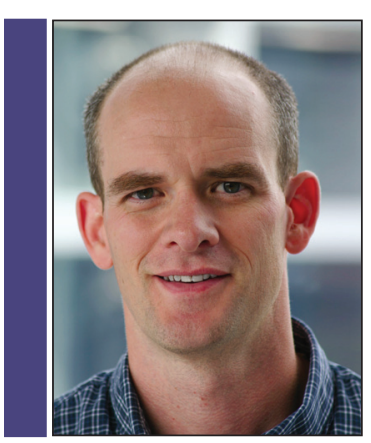

Mooney to receive Mid-Career Researcher Award for pioneering contributions in biomaterials

$\mathrm{T}$ he Materials Research Society (MRS) has named David Mooney, Robert P. Pinkas Family Professor of Bioengineering and Core Faculty Member, Wyss Institute for Biologically Inspired Engineering at Harvard University, to receive the Mid-Career Researcher Award "for pioneering contributions to the field of biomaterials, especially in the incorporation of biological design principles into materials and the use of biomaterials in mechanobiology, tissue engineering and therapeutics." Mooney will be recognized during the Awards Ceremony Wednesday, April 4 at the PCC, and will present his talk (Symposium X presentation) Thursday, April 5 during the 2018 MRS Spring Meeting in Phoenix, Ariz.

Mooney's research is driven by the question of how mammalian cells receive information from the materials in their environment. By utilizing the tools of cell and molecular biology, he studies the mechanisms by which chemical (e.g., specific cell adhesion molecules) or mechanical signals (e.g., cyclic strain) are sensed by cells, and alters their proliferation and specialization to either promote tissue growth or destruction.

Mooney uses the results from these studies to design and synthesize new biomaterials that regulate the gene expression of interacting cells for a variety of tissue-engineering and drug delivery projects. Current projects focus on therapeutic angiogenesis, regeneration of musculoskeletal tissues, and cancer therapies.

Mooney received his BS degree in chemical engineering from the University of Wisconsin-Madison, and his $\mathrm{PhD}$ degree in chemical engineering from the 
Massachusetts Institute of Technology. His contributions have led to a variety of honors, including election to both the National Academy of Engineering and the Institute of Medicine, the Society for Biomaterials Clemson Award, the IADR Distinguished Scientist Award,
NIH MERIT Award, Nature Biotechnology SciCafe Award, Einstein Visiting Fellow, and Fellow of the National Academy of Inventors. He is only the second individual to win both of Harvard's main teaching awards - the Everett Mendelsohn Excellence in Mentoring Award
(Harvard Graduate Student Council) and Phi Beta Kappa Prize for Excellence in Teaching (Harvard College).

The Mid-Career Research Award, endowed by MilliporeSigma (Sigma-Aldrich Materials Science), recognizes exceptional achievements in materials research.

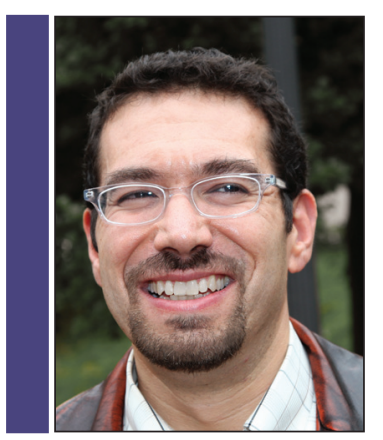

\section{Falk to receive MRS Impact Award for STEM education}

$\mathrm{M}$ ichael Falk, Department of Materials Science and Engineering, Johns Hopkins University (JHU), will receive the Materials Research Society (MRS) Impact Award during the 2018 MRS Spring Meeting "for broadened participation in STEM education in Baltimore elementary schools; for bringing attention to professional and educational climate issues faced by LGBTQ students and researchers; and for pioneered research-based methodologies for integrating computation into the Materials Science and Engineering curriculum." This award honors outstanding individuals who have displayed excellence in areas of science communication, education, advancing diversity, mentoring, or community engagement, which reflect the Society's pursuit to advance materials science and technology to improve the quality of life.

Falk is working to develop techniques that aim to extend the time scales accessible with simulation. These methods will also be extended to inherently nonequilibrium simulations. He anticipates that the simulations will enable the analysis of transitions in frictional response with respect to sliding rate and temperature.

Falk is the head of STEMAchievement in Baltimore Elementary Schools, a National Science Foundation (NSF)-funded outreach partnership between JHU and Baltimore City Schools. This \$7.4 million outreach effort to students in the third through fifth grades has altered the course of STEM instruction in Baltimore schools by integrating an innovative curriculum, teaching professional development, conducting out-of-school-time investigations, and engaging the community.

Falk has served in many capacities on campus and nationally as a champion for LGBTQ equality in the materials science disciplines. He is an advisor to both the Diverse Sexuality and Gender Alliance (a JHU LGBTQ undergraduate organization) and the JHU chapter of Out in Science, Technology, Engineering and Mathematics. For this service, he received a Diversity Recognition Award from the John Hopkins Institutions Diversity Leadership Council in 2011.

Falk received his BA degree in physics from Johns Hopkins University and his $\mathrm{PhD}$ degree in physics from the University of California, Santa Barbara. He received the NOGLSTP Educator Award, the Jon R. and Beverly S. Holt Award for Excellence in Teaching, and the NSF Career Award. He has written several articles and presentations, and has received extensive funding for materials research and outreach and education efforts.

Falk will be recognized at the Awards Ceremony on Wednesday, April 4 at the PCC.

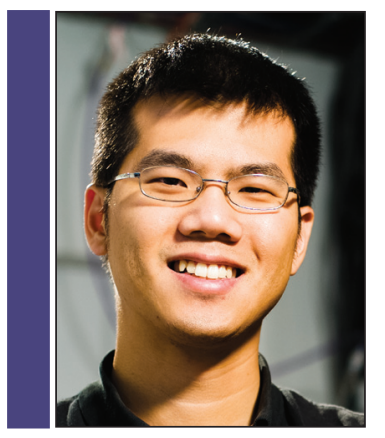

\section{Chueh named 2018} MRS Outstanding Young Investigator for ionic and electronic charge transport

W engineering at Stanford University, has been named a 2018 Materials Research Society (MRS) Outstanding Young Investigator. Chueh was cited "for groundbreaking research on ionic and electronic charge transport and interface chemistry relevant to electrochemical devices." He will receive the award Wednesday, April 4, at the 2018 MRS Spring Meeting in Phoenix and will present his talk Monday, April 2 at the PCC.

Chueh's current research focuses on ionic and electronic charge transport and interface chemistry relevant to electrochemical devices, such as batteries and fuel cells. He and his research group seek to understand and engineer 